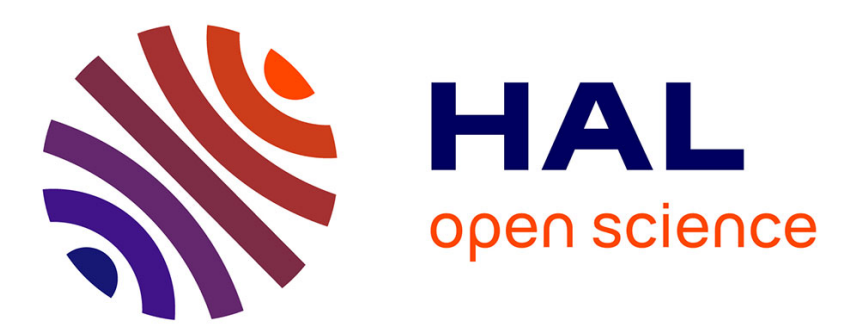

\title{
Fetal growth, early life circumstances, and risk of suicide in late adulthood
}

Phoebe Day Danziger, Richard Silverwood, Ilona Koupil

\section{To cite this version:}

Phoebe Day Danziger, Richard Silverwood, Ilona Koupil. Fetal growth, early life circumstances, and risk of suicide in late adulthood. European Journal of Epidemiology, 2011, 26 (7), pp.571-581. 10.1007/s10654-011-9592-3 . hal-00709561

\section{HAL Id: hal-00709561 https://hal.science/hal-00709561}

Submitted on 19 Jun 2012

HAL is a multi-disciplinary open access archive for the deposit and dissemination of scientific research documents, whether they are published or not. The documents may come from teaching and research institutions in France or abroad, or from public or private research centers.
L'archive ouverte pluridisciplinaire HAL, est destinée au dépôt et à la diffusion de documents scientifiques de niveau recherche, publiés ou non, émanant des établissements d'enseignement et de recherche français ou étrangers, des laboratoires publics ou privés. 
Fetal growth, early life circumstances, and risk of suicide in late adulthood

Short running head: Fetal growth, early life circumstances and risk of suicide

Phoebe Day Danziger 1, Richard Silverwood 2, and Ilona Koupil 1

1 Centre for Health Equity Studies (CHESS), Stockholm University/Karolinska Institute, Stockholm, Sweden

2 Department of Non-Communicable Disease Epidemiology, Faculty of

Epidemiology and Population Health, London School of Hygiene and Tropical Medicine, London, United Kingdom

Word count: 3993

Address for correspondence:

Ilona Koupil, Centre for Health Equity Studies (CHESS), Stockholm

University/Karolinska Institute, 10691 Stockholm, Sweden. Tel +46 8 163952, Fax +46 8 162600, Email ilona.koupil@chess.su.se 


\section{ABSTRACT}

Recent studies in Sweden and Scotland have found early life conditions to be associated with increased risk of attempted and completed suicide in adolescence and young adulthood. It is not known, however, whether early life conditions affect suicide risk throughout the life course, from adulthood into old age.

We examined the effects of early life conditions, including markers of fetal growth, and social and economic characteristics in adulthood, on risk of suicide by violent and non-violent methods in women and men aged 31-87 years using Cox regression. 11,650 women and men born at the Uppsala University Hospital in Sweden between 1915-1929 were followed from 1960 until 2002 using linked records from obstetric archives, Census, population and mortality registries. During 435,039 person-years of follow-up 161 completed suicides (104 in males, 57 in females) were observed. An inverse association was found between lower birthweight-for-gestational age and risk of violent suicide in females, although the association did not reach the conventional level of statistical significance (minimally adjusted HR 2.02, 95\% CI (0.88-4.63); Table 5). Being male, unmarried, and in the "other or unknown" social class category in adulthood were independently associated with increased rates of suicide. There was a weak association between higher maternal parity and suicide rates.

Our findings suggest differences in effects of fetal growth patterns and perinatal circumstances on suicide risk later in life, and suggest that suicide in adults and in the elderly may be influenced by a different combination of factors than those that influence suicide in adolescence and young adulthood. 
Key words: early life, fetal growth, gender differences, life course, socio-economic position, suicide 


\section{INTRODUCTION}

Adverse perinatal circumstances such as impaired fetal growth and unfavorable socioeconomic and psychosocial conditions at birth have been linked to a number of later life health outcomes, including coronary heart disease, cerebrovascular disease, and diabetes mellitus [1-4]. The developmental origins of health and "fetal programming" hypotheses pioneered by David Barker and colleagues in the 1980s have given rise to a deepening understanding of the ways in which early life circumstances may lead to alterations in development and in metabolic and hormonal systems, which in turn may lead to altered risk of disease throughout the life course [5].

More recently, there has been increasing evidence that adverse conditions in utero and in early life, both biological and social, are also associated with long-term mental health outcomes. Studies have demonstrated associations between low birth weight for gestational age or small body size at birth and higher incidence of depression [68], attention-deficit hyperactivity disorders (ADHD) [9], and general psychological distress and disturbances [10].

Studies by Mittendorfer-Rutz et al. [11-12] in Sweden and Riordan et al. [13] in Scotland have produced intriguing evidence for a relationship between adverse perinatal conditions and suicidal behavior, including attempted and completed suicide, in adolescents and young adults. Using a Swedish cohort of males and females followed until age 19-26, Mittendorfer-Rutz et al. [11] found low birth weight for gestational age to be associated with increased risk of completed suicide, while 
short birth length for gestational age was associated with increased risk of attempted suicide. Following up on these results, Mittendorfer-Rutz et al. [12] found associations in Swedish male military conscripts between impaired fetal linear growth and low birth weight, and higher risk of suicide attempts, particularly attempts of a violent nature, in adolescence and young adulthood. Similarly, Riordan et al. [13] found that high maternal parity, low maternal education, low maternal age at birth, and low birth weight were associated with higher rates of suicide in females and males aged 12-34 at the end of the follow-up period. However, not all studies [14-16] have produced similar results regarding a connection between low birth weight and increased suicide risk.

In an article on a life course perspective of suicide, Gunnell and Lewis [17] provide a broad overview of the range of interconnected factors that contribute to suicide risk, including family, psychiatric, and socio-economic conditions, as well as life events and cultural dynamics.

Using data from Norway, Gravseth et al. [16] demonstrated several risk factors for suicide in young adulthood related to early life variables, including higher birth order, variation in maternal marital status, parental suicide, mental health indicators, low BMI, and lower educational level by age 19 . Their results suggest that a myriad of individual and family characteristics may play a role in suicide risk. Similarly, Kristensen et al. [18] provide evidence for the role of social inequities in early life in later disparities in psychiatric outcomes. Strand and Kunst [19], interestingly, found higher suicide mortality among females with higher childhood socio-economic status, suggesting complex interplay between socio-economic factors and mental health and 
well-being.

In many industrialized countries, the highest rates of suicide are found in the elderly, particularly in elderly males. In Sweden in 2002, the highest suicide rate for men and women combined was found in the $75+$ age bracket $(20.3$ per 100,000$)$. The highest suicide rate for men only was also found for ages $75+(36.5$ per 100,000$)$, while the highest rate for women only was found in the 55-64 years age group (12.6 per 100,000) (20). Estimates of worldwide distribution of suicide rates by age and gender have found roughly similar patterns.

While much research has been done on etiology and triggering factors for suicide in older adults and in the elderly [21-26], to our knowledge there have been no studies examining whether early life conditions affect risk for suicide past adolescence and early adulthood. We examine the relationship between early life factors - including birth weight, birth length, gestational age, and familial social characteristics - and risk of suicide from early adulthood through old age.

\section{METHODS}

\section{Sources of data:}

This study is based on data from the Uppsala Birth Cohort Study, comprised of all births that occurred at the Uppsala University Hospital in Uppsala, Sweden, between 1915-1929 [27]. The archived obstetric records that contain in-depth information regarding medical and sociodemographic characteristics of cohort members and their parents at the time of birth of the cohort members have been linked to the Census, 
population and mortality registers using the unique personal identity numbers.

In total, the Uppsala Birth Cohort consists of 14,193 live births. There were 12,168 women and men who were still alive and/or living in Sweden in 1947 and whose personal registration number was known. In our analysis, we used information on 11,650 cohort members who were singleton births and were alive and resident in Sweden in 1960 with a known personal number. Members of the cohort were 31-45 years old at the beginning of the follow-up period on 1 January 1960, and 73-87 years old at the end of follow-up on 31 December 2002. Data were censored for emigration and deaths from causes other than suicide.

Birth weight (in grams), birth length (in centimeters), gestational age based on last menstrual period, mother's parity and age, and social characteristics of the family when the study subjects were born were abstracted from the archived obstetric records. Marital status and social class in adulthood were obtained from the 1960 Census. Date and cause of deaths was obtained from the mortality register (National Board of Health and Welfare) and date of emigration from the population register (Statistics Sweden).

International Classification of Disease (ICD) codes from ICD versions 7, 8, 9, and 10 - in use in Sweden between 1958-1968, 1969-1986, 1987-1996, and 1997-present were used to determine outcome variables. Deaths resulting from self-inflicted injury are coded for by E-963 and E970-979 in ICD-7, E950-959 in ICD-8 and ICD-9, and X60-84 in ICD-10. Deaths resulting from events of undetermined intent are coded for by Y68 in ICD-7, E980-989 in ICD-8 and ICD-9, and by Y10-34 in ICD-10. Deaths 
resulting from events of undetermined intent, i.e. due to injuries that may or may not have been purposefully self-inflicted, are included in this analysis.

\section{Statistical analysis:}

To handle the relatively small amount of missing data on the early and later life characteristics we used a multiple imputation (MI) approach [28]. As well as all the variables included in the analysis models, described above, the imputation model also included date of birth, education level in 1960, time until suicide or censoring, and indicator variables for suicide and violent suicide. Fifty imputed data sets were obtained via chained equations [29] using the ice command [30] in Stata 11.

Data analysis was performed using Cox regression in Stata 11. All models were fitted on the age scale with adjustment for calendar period (time since the beginning of follow-up in 1960). Standard errors were calculated allowing for the clustered nature of the data (the 11,650 subjects in the study were born to 9519 mothers). Effect modification by gender was assessed using the likelihood ratio test. Results are presented separately for suicide by violent means in addition to all suicides combined.

The following variables were treated categorically and entered as indicator variables: birth weight $(<2500 \mathrm{~g}, 2500 \mathrm{~g}-3249 \mathrm{~g}, 3250-3749 \mathrm{~g}, 3750-4499 \mathrm{~g}$, and $4500 \mathrm{~g}+)$, gestational age $(<38,38-41$ and $42+$ weeks $)$, maternal age at birth $(15-24,25-34$ and $35+$ years), maternal parity at birth (1, 2-3 and 4+), maternal marital status at birth (married or other), social class at birth (non-manual, self-employed or farmer, manual and other), adult marital status (married or other), and social class in 1960 (non- 
manual, self-employed or farmer, manual and other). Birth weight was considered in terms of tertiles of birthweight-for-gestational age. Sex-specific Z-scores of birth weight for gestational age were calculated for each week of gestation separately, for births of 30+ weeks of gestation, using the complete cohort of live births as a standard.

Cox regression models were first used to assess the relationships between each early and later life characteristic and suicide risk, minimally adjusted for age and calendar period (split into the periods 1960-69, 1970-79, 1980-89 and 1990-2002). Further adjustment was then conducted in a sequential manner. Firstly for the other characteristic within the same characteristic type as follows: maternal characteristics (maternal age and maternal parity); early life physical characteristics (birth weightfor-gestational age and gestational age); early life socioeconomic characteristics (social class at birth and mother's marital status); and later life socioeconomic characteristics (adult social class and adult marital status); then for all other maternal and early life characteristics; and finally later life socioeconomic characteristics were added. All analyses were repeated including birth length as a categorical value $(<50$ $\mathrm{cm}, 50-51 \mathrm{~cm}, 52+\mathrm{cm})$. The proportional hazards assumption for each of the exposure variables was checked by examination of hazard plots and the Schoenfeld test. For explanatory variables with more than two levels, tests for trend were conducted by assigning consecutive integer values to each level, entering the variable into the model as if continuous, and examining the Wald test statistic.

In addition to the MI analysis, all the modeling was repeated on a complete case basis for comparison. 
The study was approved by the Regional Ethics committee in Stockholm.

\section{RESULTS}

Table 1 gives characteristics of the individuals in the Uppsala Birth Cohort who committed suicide between the years 1960-2002. During 435,039 person-years of follow-up 161 completed suicides (104 in males, 57 in females) were observed, of which 75 (49 males, 26 females) were via violent methods. Emigration and deaths from causes other than suicide resulted in censoring for 125 and 5030 subjects respectively.

The mean standardized birth weight $\mathrm{z}$-score, length, and gestational age at birth for the 11,650 cohort members included in the analysis were $0.025,51.2 \mathrm{~cm}$, and 39.4 weeks for males, and $0.033,50.5 \mathrm{~cm}$, and 39.5 weeks for females.

The crude incidence rate of completed suicide was 47.6 per 100,000 in males and 26.3 per 100,000 in females. Crude incidence rates for completed suicide and completed suicide via violent methods by early and later life characteristics are shown in Table 2. Also shown in Table 2 is the number of missing values for each variable, with birthweight-for-gestational age having most $(355,3.0 \%)$. Conducting a complete case analysis using only study participants with available data on all the variables in Table 2 would decrease the sample to 11,080 (95.1\% of the original sample). Under the MI approach all 11,650 subjects were used. 
No evidence was found of effect modification by gender for any of the early life and later life characteristics when considering completed suicide overall (all p>0.1), so results from combined male-female Cox regression models are shown in Table 3. For completed suicide via violent methods, only birthweight-for-gestational age was found to interact with gender $(\mathrm{p}=0.002)$. To increase power and maintain comparability with the completed suicide overall results, combined male-female results are again presented in Table 3. However, additional gender-stratified results for birthweight-for-gestational age are given in Table 4. Only the minimally and fully adjusted results are presented. No evidence was found to contradict the proportional hazards assumption for any of the variables examined.

\section{Gender}

Males were almost twice as likely as females to die from suicide by all methods (minimally adjusted HR 1.82, 95\% CI 1.32-2.51) and by violent methods (HR 1.92, 95\% CI 1.20-3.07), with little attenuation in the fully adjusted model.

\section{Maternal Characteristics}

No associations were found between maternal age and suicide by all methods. Some evidence was found of a positive association was found between increasing maternal parity and rate of suicide by all methods. For subjects born to mothers with four or more children the HR was 1.44 ( $95 \%$ CI $0.97-2.13$ ) relative to those born to mothers with no other children in the minimally adjusted model. When early life and adult social characteristics were controlled for, there was little evidence of this association. 
When the outcome was restricted to violent suicide deaths only the magnitude of the association remained similar but the confidence intervals widened due to the lack of power.

\section{Early life physical characteristics}

No association was found between birthweight-for-gestational age and rate of suicide by all methods (Table 3). Due to the observed interaction between birthweight-forgestational age and violent suicide, separate gender-stratified results are presented for this risk factor. However, as the original categorization of birthweight-for-gestational age resulted in only two violent suicides among females in the highest tertile (Table 2), for this sub-analysis we re-classified subjects into a two-level variable by splitting at the median. Using this variable there was still some evidence of interaction $(\mathrm{p}=0.03$ ), but there were more (eight) violent suicides among females in the highest category. Lower birthweight-for-gestational age was associated with double the hazard of violent suicide in females (minimally adjusted HR 2.02, 95\% CI 0.88-4.63; Table 4), although this association did not reach the conventional level of statistical significance. Adjusting for other early life characteristics and adult social characteristics did not diminish the strength of the association.

All analyses were repeated to include birth length, but this variable had no significant effect on the results. Results are reported with birth length excluded from the models.

No associations we observed between gestational age and risk of suicide. 


\section{Early life socioeconomic characteristics}

There was no evidence of associations between either maternal marital status at birth or social class at birth and risk of suicide.

\section{Later life socioeconomic characteristics}

Subjects whose social class was categorized as 'Other or unknown' in 1960, a category which included those who were unemployed or whose employment status did not fall into the other classification categories, were more than twice as likely to commit suicide by all methods (HR 2.11, 95\% CI 1.21-3.68 in the minimally adjusted model) relative to non-manual workers, though this was attenuated after further adjustment. There was also some evidence that being self-employed or a farmer had a protective effect (HR 0.55, 95\% CI 0.31-1.00).

Subjects who were unmarried based on the 1960 Census were almost three times as likely to commit suicide when considering all methods (HR 2.82, 95\% CI 2.04 to 3.91 in the minimally adjusted model) and violent methods only (HR 2.54, 95\% CI 1.56 to 4.14). These HRs were only slightly attenuated in the fully adjusted models.

The results from the complete case analysis (not shown) were very similar to those in the MI analysis. For variables with little or no missing data, the estimated hazards were essentially unchanged.

\section{DISCUSSION}


In this cohort study of 11,650 subjects followed for over 40 years the rate of suicide was found to be much higher in males, both overall and for violent suicides only. There was some evidence that higher maternal parity increased the rate of suicide and that lower birthweight-for-gestational age increased the rate of violent suicide in females. Being in the "other or unknown" social class category in adulthood was associated with an increased rate of suicides, whereas being self-employed or a farmer was found to have a protective effect. Being unmarried in adulthood was strongly associated with suicide. The results suggested broadly similar effects of early life and social characteristics on both violent and non-violent suicide risk.

One limitation of the present analysis was a lack of statistical power. Although the total number of suicides (161) allowed overall associations to be examined in some detail, restricting the analysis to violent suicides (75) and/or stratifying by gender resulted in levels of power which made the detection of small effects difficult. In particular, estimated hazards which differed considerably from the null but were not statistically significant at the conventional level of 0.05 may only have been so due to the lack of power. Additionally, further interactions with sex (i.e. male-female differences) may well have been observed had power been greater.

Although the amount of missing data in this analysis was small (the maximum on any of the early or later life characteristics was 3.0\%), the use of a MI approach means that any potential bias due to missingness should have been accounted for, under the assumption of missing at random [31]. 


\section{Fetal Growth}

Differences were found between men and women when considering associations between size at birth as a marker of fetal growth and later suicide risk. The most interesting result was an association between lower birthweight-for-gestational age and suicide risk by violent methods in females (Table 4), though this did not reach the conventional level of statistical significance. This trend was not expected given previous results showing no gender differences between fetal growth and later risk for completed and attempted suicide [11-13], affective disorders [8], and psychiatric disease [10]. The gender effect found in this study suggests that in adulthood,and old age, risk factors may diverge for males and females. One study [7] found a positive association between low birth weight and depression in adolescent females but not males, but it is unclear why impaired fetal growth may increase susceptibility to depression and suicide in females but not males.

The Swedish and Scottish studies of early life conditions and suicide $[11,13]$ found no gender differences in their results, but there are many established differences between type and distribution of suicidal behavior among males and females in different age groups [17]. For example, in the United States adolescent females attempt suicide twice as frequently as adolescent males, but adolescent males commit suicide at a nearly four-fold rate compared to adolescent females [32]. Because of these differences in distribution of suicidal behavior between males and females throughout the life course, and because of known gender differences in growth trajectory in utero, which may be connected to long-term physiological and psychiatric outcomes, it is important to consider the possibility that risk factors for suicide may be different for men and women during different life stages. 
We found no association between birth length and suicide risk despite strong negative associations being found in previous studies [11-12, 33]. It is possible that birth length is a factor involved in the etiology of suicide earlier in life, as the previous studies focused on younger subjects, but that birth length drops out as a variable of importance for suicides later in life.

Maternal stress may be a key factor leading to both decreased birth weight and programming of the fetal HPA axis. Maternal stress, which may be related to depression, anxiety, or other mental health issues, has been shown to increase risk for low birth weight, which in turn is associated with greater risk of a wide range of psychiatric issues for the child, both early and later in life. Low birth weight has been shown to predict elevated cortisol levels in adulthood [34], and elevated cortisol levels are strongly correlated with depression, which is a strong predictor of suicidal behavior, including in the elderly specifically $[26,35]$.

However, evidence has also been found for a connection between hypoactivity of the HPA-axis, i.e. hypocortisolemia [36] and suicidal behavior in a sample of Swedish psychiatric patients, suggesting that there may be multiple pathways of HPA-axis dysregulation involved in suicidal behavior, including both hyper- and hypo-activity. In another relevant study, Kajantie et al. [37] found an inverse U-shaped association between birth weight and cortisol response to psychosocial stress in female and male members of the Helsinki Birth Cohort aged 60-70, providing more evidence for the existence of both hyper- and hypoactivity of the HPA-axis in the context of stress response. 
Jokinen and Nordström [38] found that in elderly patients hospitalized for mood disorders such as depression, impaired functioning of the HPA-axis, measured by inability to suppress cortisol in response to the dexamethasone suppression test (DST), was a strong predictor of suicide, indicating possible continuity between in utero HPA-axis programming and dysregulation of cortisol later in life. Interestingly, Jokinen and Nordström found gender differences in cortisol responses to the DST, with only female suicide victims showing significantly increased cortisol levels compared to those patients who did not commit suicide, underlining the need for further consideration of gender- and age-specific risk factors.

\section{Early and Later Life Social Characteristics}

The association between higher maternal parity and increased risk of suicide is in accord with previous studies linking higher birth order to raised suicide risk [11, 13]. The average completed family size in Sweden in the early $20^{\text {th }}$ century was under 2 , in contrast to more than 4 in cohorts born between 1736 and 1856 [39]. The current data is limited because completed family size is unknown, but the results suggest that there may be effects of having many siblings, or being the youngest of many siblings, on offsprings' psychiatric outcomes.

An earlier study on grand multiparity (i.e. mothers who have had at least six deliveries) in a Finnish birth cohort found increased risk of depression, alcoholism, and non-schizophrenic psychoses, among children of grand multiparous mothers [40]. It is possible that for a child growing up in a household with many siblings, parental attention and support may be spread thinner than is needed for that child's adequate 
social and psychological development, which may result in greater vulnerability to psychiatric issues and suicidal behavior later in life. Multiparity and/or large family size may also be correlated with adverse psychological development through a link with maternal stress, which has been connected with both short- and long-term effects on offsprings' physiological, psychological, and neurological development. However, our analysis of data on maternal parity only does not allow us to make a clear distinction between potential independent effects of maternal parity (birth order) and family size, and further studies are needed to clarify these relationships.

It is notable that in our study maternal age at birth was neither independently associated with suicide nor important as a mediating factor in the multivariable models including parity, while previous studies showed strong effects $[11,13]$.

Despite evidence pointing to a connection between lower socioeconomic class at birth, estimated by parental occupation, education level, or receipt of social assistance, and adverse outcomes for offspring ranging from affective disorders [41] to suicide $[11,13,42]$, we were not able to replicate or extend these findings in our study. The only measure of social class that was associated with suicide risk in our analyses was a nearly three-fold higher risk of suicide in those males categorized as having a social class of "other or unknown" according to the 1960 census, which was expected as this class is likely to include individuals suffering from psychiatric disorders that are strongly correlated with suicidal behavior, as well as individuals suffering from other life problems such as debilitating physical illness which may lead both to unemployment and increased risk of suicide. It is likely that this association was not found in females because females' social class would most likely have been 
classified in the 1960 census data on the basis of their husbands' occupation, which would be a less accurate measure of women's occupational status and work environment, and unlikely to be a consequence of women's own impaired mental health status or personal characteristics.

Our results replicated the general findings of numerous studies demonstrating that individuals who are not married have significantly higher risk of suicide [43-45], but the relatively crude distinction between simply married and not married available in this study likely obscures more complex patterns among subsets who are divorced, widowed, or married but not cohabitating.

\section{Strengths and Limitations of Methodology}

The overall quality of the Swedish registry system is excellent. There is nearly complete information on overall mortality and cause of death during our follow-up period of 1960-2002. One particular strength of this longitudinal, prospective study design is that the data on characteristics at birth come from a separate source to the data about mortality and cause of death, from the Swedish Cause of Death register, and the data about adult social characteristics, from the 1960 Population and Housing Census. Having multiple independent but reliable sources of data reduces the risk of bias.

The use of a MI approach should have accounted for any potential bias due to the small amount of missing data. However, the lack of statistical power in the analysis made the detection of small effects, particularly interaction terms, difficult. It is thus important that the associations explored in this study are investigated further in 
different populations with greater power.

Marital status and social class in adulthood were only observed at a single time point (in 1960 when subjects were age 31-45) so may not be perfect proxies of lifetime statuses. This is unlikely to be a serious issue for social class, but for marital status, which can change markedly over the life course, this may have led to attenuation of the estimated associations.

As Mittendorfer-Rutz et al. [11] and Riordan et al. [13] discuss, significant percentages of deaths officially classified as events of undetermined intent have been shown to actually be suicides in Sweden and in the United Kingdom, for example. In addition, because the years of follow-up in this study include an historical period during which there may have been increased stigma attached to the act of suicide and less cultural awareness and acceptance of mental health issues in Sweden, we argue that there may have been a bias towards reporting deaths resulting from self-inflicted injury as events of undetermined intent.

The rate of suicide in the cohort was slightly higher than the overall population suicide rate in Sweden. In 2006, the suicide rates in Sweden per 100,000 for males were 13.5 for ages $25-34$ years old, 20.7 for ages $35-44,25.3$ for ages $45-54,25.8$ for ages 55-64, 29.1 for ages $65-74$, and 36.5 for ages $75+$. For females, the rates were 7.3 for ages 25-34, 10.8 for ages 35-44, 13.0 for ages 45-54, 9.5 for ages 55-64, 9.2 for ages $65-74$, and 9.9 for ages $75+(20)$. Because this study includes suicides in elderly people, and the elderly have much higher rates of physical illness in general than younger members of the population, it is possible that suicide deaths in elderly 
cohort members were misnotated as death due to physical illness. If this is the case, our effects may be underestimated.

\section{Conclusions}

Suicide is a major public health problem both in Sweden and globally, across the life span but particularly in the elderly, who have the highest suicide rates in most industralized countries [20,46]. Moreover, suicide rates are increasing in many developing countries [47], suggesting that knowledge gained from historical cohorts such as the Uppsala Birth Cohort may be relevant to many parts of the world today.

The results of our study suggest that among adult and old people, certain early life characteristics that were found to be associated with increased suicide rates in adolescents and young adults in previous studies [11-13] may no longer be as significant. While impaired fetal growth remained a possible risk factor for females in our study, as did higher birth order or greater maternal parity, adult life circumstances, such as social class and marital status, were found to be most strongly related to suicide in our cohort.

As the results of this study demonstrate, there appear to be many potential variations in risk factors for suicide behaviour during different life stages, and between males and females. In order to introduce effective prevention and intervention strategies aimed at reducing suicide rates, it is crucial to further explore the nature of these variations and develop appropriate strategies targeted at specific age groups and genders. 


\section{ACKNOWLEDGEMENTS}

We would like to thank Rawya Mohsen for help with data management, and to Ellenor Mittendorfer-Rutz, Illka Mäkinen and Britt af Klinteberg for helpful comments on our earlier drafts. The UBCoS Multigen study is supported by grants from the Swedish Council for Working Life and Social Research and the Swedish Research Council. PDD was supported by the The Fulbright Commission:

Commission for Educational Exchange between the United States and Sweden while working on this project. IK is currently funded by the Swedish Council for Working Life and Social Research. The funders were not involved in the study design or execution and the views and conclusions expressed in this manuscript are the responsibility of the authors. 


\section{REFERENCES}

1. Barker DJ. Fetal programming of coronary heart disease. Trends Endocrinol Metab 2002;13:364-68.

2. Gluckman PD, Hanson MA, Pinal C. The developmental origins of adult disease. Matern Child Nutr. 2005;1:130-41.

3. Lawlor DA, Ronalds G, Clark H, Smith GD, Leon DA. Birth weight is inversely associated with incident coronary heart disease and stroke among individuals born in the 1950s: findings from the Aberdeen Children of the 1950s prospective cohort study. Circulation 2005;112:1414-18.

4. Ong KK, Dunger DB. Birth weight, infant growth, and insulin resistance. Eur J Endocrinol. 2004;151:U131-39.

5. Barker DJ. The origins of the developmental origins theory. J Intern Med. $2007 ; 261: 412-17$

6. Alati R, Lawlor DA, Mamun AA, Williams GM, Najman JM, O’Callaghan M, Bor W. Is there a fetal origin of depression? Evidence from the Mater University Study of Pregnancy and its outcomes. Am J Epidemiol. $2007 ; 165: 575-82$

7. Costello EJ, Worthman C, Erkanli A, Angold A. Prediction From Low Birth Weight to Female Adolescent Depression: A Test of Competing Hypotheses. Arch Gen Psychiatry 2007;64:338-44.

8. Gale CR, Martyn CN. Birth weight and later risk of depression in a national birth cohort. Br J Psychiatry 2004;184:28-33.

9. Lahti J, Räikkönen K, Kajantie E, Heinonen K, Pesonen AK, Järvenpää AL, Strandberg T. Small body size at birth and behavioural symptoms of ADHD in children aged five to six years. J Child Psychol Psychiatry 2006;47:1167-74. 
10. Wiles NJ, Peters TJ, Leon DA, Lewis G. Birth weight and psychological distress at age 45-51 years: results from the Aberdeen Children of the 1950s cohort study. Br J Psychiatry 2005;187:21-8.

11. Mittendorfer-Rutz E, Rasmussen F, Wasserman D. Restricted fetal growth and adverse maternal psychosocial and socioeconomic conditions as risk factors for suicidal behaviour of offspring: a cohort study. Lancet 2004;364:1135-40.

12. Mittendorfer-Rutz E, Wasserman D, Rasmussen F. Fetal and childhood growth and the risk of violent and non-violent suicide attempts: a cohort study of 318953 men. J. Epidemiol. Community Health 2008;62:168-173.

13. Riordan DV, Selvaraj S, Stark C, Gilbert JSE. Perinatal circumstances and risk of offspring suicide: Birth cohort study. Br J Psychiatry 2006;189:502-7.

14. Li CI, Daling JR, Emanuel I. Birthweight and risk of overall and causespecific childhood mortality. Paediatr Perinat Epidemiol 2003;17:164-70.

15. Osler M, Nybo Andersen AM, Nordentoft M. Impaired childhood development and suicidal behaviour in a cohort of Danish men born in 1953. J Epidemiol Community Health 2008;62:23-28.

16. Gravseth HM, Mehlum L, Bjerkedal T, Kristensen P. Suicide in young Norwegians in a life course perspective: population-based cohort study. J Epidemiol. Community Health 2010;64:407-12.

17. Gunnell D, Lewis G. Studying suicide from the life course perspective: implications for prevention. Br J Psychiatry 2005;187:206-8.

18. Kristensen P, Gravseth HM, Bjerkedal T. Influence of early life factors on social inequalities in psychiatric outcomes among young adult Norwegian men. Eur J Public Health 2010;20:517-23.

19. Strand BH, Kunst A. Childhood socioeconomic status and suicide mortality in 
early adulthood among Norwegian men and women. A prospective study of Norwegians born between 1955 and 1965 followed for suicide from 1990 to 2001. Soc Sci Med 2006;63:2825-34.

20. World Health Organization. http://www.who.int/mental_health/prevention/suicide/suicideprevent/en/index. html. Accessed October 17, 2010.

21. Conwell Y, Duberstein PR, Caine ED. Risk Factors for Suicide in Later Life. Biol Psychiatry 2002;52:193-204.

22. Duberstein PR, Conwell Y, Conner KR, Eberly S, Caine ED. Suicide at 50 years of age and older: perceived physical illness, family discord and financial strain. Psychol Med. 2004;34:137-46.

23. Harwood DMJ, Hawton K, Hope T, Harriss L, Jacoby R. Life problems and physical illness as risk factors for suicide in older people: a descriptive and case-control study. Psychol Med. 2006;36:1265-74.

24. Juurlink DN, Herrmann N, Szalai JP, Kopp A, Redelmeier DA. Medical Illness and the Risk of Suicide in the Elderly. Arch Intern Med. 2004;164:1179-84.

25. Pearson JL, Brown GK. Suicide Prevention in Late Life: Directions for Science and Practice. Clin Psychol Rev. 2000;20:685-705.

26. Rubenowitz E, Waern M, Wilhelmson K, Allebeck P. Life events and psychosocial factors in elderly suicides - a case-control study. Psychol Med. 2001;31:1193-1202.

27. Koupil I. The Uppsala studies on developmental origins of health and disease. J Intern Med 2007;261:426-36.

28. Kenward MG, Carpenter J. Multiple imputation: current perspectives. Stat 
Methods Med Res 2007;16(3):199-218.

29. van Buuren S, Boshuizen HC, Knook DL. Multiple imputation of missing blood pressure covariates in survival analysis. Stat Med 1999;18(6):681-94.

30. Royston P. Multiple imputation of missing values: Further update of ice, with an emphasis on categorical variables. Stata Journal 2009;9:466-77.

31. Little RJA, Rubin DB. Statistical Analysis With Missing Data. New York: Wiley; 2002.

32. U.S. Department of Health and Human Services. Mental Health: A Report of the Surgeon General. U.S. Department of Health and Human Services, Substance Abuse and Mental Health Services Administration, Center for Mental Health Services, National Institutes of Health, National Institute of Mental Health: Rockville, MD, 1999.

33. Whitley E, Rasmussen F, Tynelius P, Batty GD. Physical stature and methodspecific attempted suicide: cohort study of one million men. Psychiatry Res 2010;179:116-8.

34. Phillips DI, Walker BR, Reynolds RM, Flanagan DE, Wood PJ, Osmond C, Barker DJ, Whorwood CB. Low birth weight predicts elevated plasma cortisol concentrations in adults from 3 populations. Hypertension 2000;35:1301-6.

35. Waern M, Rubenowitz E, Wilhelmson K. Predictors of suicide in the old elderly. Gerontology 2003;49:328-34.

36. Lindqvist D, Isaksson A, Träskman-Bendz L, Brundin L. Salivary cortisol and suicidal behavior - A follow-up study. Psychoneuroendocrinology 2008;33:1061-8.

37. Kajantie E, Feldt K, Räikkönen K, Phillips DI, Osmond C, Heinonen K, Pesonen AK, Andersson S, Barker DJ, Eriksson JG.. Body size at birth 
predicts hypothalamic-pituitary-adrenal axis response to psychosocial stress at age 60 to 70 years. Endocrinol Metab. 2007;92:4094-100.

38. Jokinen J, Nordström P. HPA axis hyperactivity as suicide predictor in elderly mood disorder inpatients. Psychoneuroendocrinology 2008;33:1387-93.

39. Eckstein Z, Mira P, Wolpin KI. A quantitative analysis of Swedish fertility dynamics: 1751-1990. Rev Econ Dynam. 1999;2:137-65.

40. Kemppainen L, Mäkikyrö T, Jokelainen J, Nieminen P, Järvelin MR, Isohanni M. Is grand multiparity associated with offsprings' hospital-treated mental disorders? A 28-year follow-up of the North Finland 1966 birth cohort. Soc Psychiatry Psychiatr Epidemiol. 2000;35:104-108.

41. Mäki NE, Martikainen PT. Socioeconomic differences in suicide mortality by sex in Finland in 1971-2000: a register-based study of trends, levels, and life expectancy differences. Scand J Public Health 2007;35:387-95.

42. Rojas Y, Stenberg SA. Early life circumstances and male suicide - a 30-year follow-up of a Stockholm cohort born in 1953. Soc Sci Med 2010;70:420-7.

43. Kposowa AJ. Marital status and suicide in the National Longitudinal Mortality Study. J Epidemiol Community Health 2000;54:254-61.

44. Luoma JB, Pearson JL. Suicide and Marital Status in the United States, 19911996: Is Widowhood a Risk Factor? Am J Public Health 2002;92:1518-22.

45. Yip PS, Thorburn J. Marital status and the risk of suicide: experience from England and Wales, 1982-1996. Psychol Rep 2004;94:401-7.

46. Gunnell D, Miller M. Strategies to prevent suicide. BMJ 2010;341:c3054.

47. Vijayakumar L, Nagaraj K, Pirkis J, Whiteford H. Suicide in Developing Countries: Frequency, Distribution, and Association with Socioeconomic Indicators. Crisis 2005;26:104-111. 


\section{Tables}

See separate file.

Table 1: Characteristics of the Uppsala birth cohort members born 1915-1929 who completed suicide between 1960-2002 ( $\mathrm{n}=11,650)$.

\begin{tabular}{|l|c|c|}
\hline & Males & Females \\
\hline Number of subjects & 6057 & 5593 \\
Number of completed suicides (\% of cohort) & $104(1.7)$ & $57(1.0)$ \\
Number of suicides determined to be intentional (\% of male or female suicides) & $82(78.9)$ & $41(71.9)$ \\
Number of deaths classified as undetermined intent (\% of male or female suicides) & $22(21.2)$ & $16(28.1)$ \\
Number of suicides using violent methods (\% of male or female suicides) & $49(47.1)$ & $26(45.6)$ \\
Number of suicides using non-violent methods (\% of male or female suicides) & $55(52.9)$ & $31(54.4)$ \\
Mean age in years at death from suicide (SD) & $57.8(11.3)$ & $57.2(11.6)$ \\
\hline
\end{tabular}


Table 2: Crude incidence rates for completed suicide and completed suicide via violent methods by early life and later life characteristics ( $\mathrm{n}=11,650)$.

\begin{tabular}{|c|c|c|c|c|c|c|c|c|c|c|c|c|c|}
\hline & \multirow[b]{2}{*}{$\begin{array}{c}\mathrm{n}(\%) \\
\text { missing }\end{array}$} & \multicolumn{6}{|c|}{ Males $(n=6057)$} & \multicolumn{6}{|c|}{ Females $(n=5593)$} \\
\hline & & $\mathrm{n}(\%)$ & $\begin{array}{l}\text { Person-years } \\
\text { at risk }\end{array}$ & Events & $\begin{array}{l}\text { uicide } \\
\text { Crude } \\
\text { incidence } \\
\text { rate }^{\mathrm{A}}\end{array}$ & $\begin{array}{l}\text { Violen } \\
\text { Events }\end{array}$ & $\begin{array}{l}\text { At suicide } \\
\text { Crude } \\
\text { incidence } \\
\text { rate }^{\mathrm{A}}\end{array}$ & $\mathrm{n}(\%)$ & $\begin{array}{l}\text { Person-years } \\
\text { at risk }\end{array}$ & Events & $\begin{array}{l}\text { licide } \\
\text { Crude } \\
\text { incidence } \\
\text { rate }^{\mathrm{A}}\end{array}$ & Violen & $\begin{array}{l}\text { Crude } \\
\text { Cruicide } \\
\text { incidence } \\
\text { rate }^{\mathrm{A}}\end{array}$ \\
\hline Maternal age (years) & $6(0.1)$ & & & & & & & & & & & & \\
\hline $15-24$ & & $1943(32.1)$ & 69,679 & 31 & 44.5 & 12 & 17.2 & $1853(33.2)$ & 71,944 & 17 & 23.6 & 7 & 9.7 \\
\hline $25-34$ & & 2929 (48.4) & 105,790 & 54 & 51.0 & 29 & 27.4 & $2675(47.9)$ & 103,661 & 26 & 25.1 & 11 & 10.6 \\
\hline $35+$ & & $1183(19.5)$ & 42,832 & 19 & 44.4 & 18 & 18.7 & $1061(19.0)$ & 40,897 & 14 & 34.2 & 8 & 19.6 \\
\hline Maternal parity & $2(0.0)$ & & & & & & & & & & & & \\
\hline 1 & & $2389(39.5)$ & 86,578 & 29 & 33.5 & 14 & 16.2 & $2204(39.4)$ & 85,746 & 24 & 28.0 & 10 & 11.7 \\
\hline $2-3$ & & $2186(36.1)$ & 78,762 & 43 & 54.6 & 19 & 24.1 & 2094 (37.4) & 80,731 & 19 & 23.5 & 11 & 13.6 \\
\hline $4+$ & & $1480(24.4)$ & 52,967 & 32 & 60.4 & 16 & 30.2 & $1295(23.2)$ & 50,178 & 14 & 27.9 & 5 & 10.0 \\
\hline Birthweight-for-gestational age & $355(3.0)$ & & & & & & & & & & & & \\
\hline Lowest tertile & & $1899(32.3)$ & 68,362 & 35 & 51.2 & 13 & 19.0 & $1734(32.1)$ & 66,948 & 25 & 37.3 & 13 & 19.4 \\
\hline Middle tertile & & $1987(33.8)$ & 71,526 & 30 & 41.9 & 13 & 18.2 & $1829(33.8)$ & 70,817 & 19 & 26.8 & 10 & 14.1 \\
\hline Highest tertile & & $2000(34.0)$ & 72,281 & 38 & 52.6 & 22 & 30.4 & $1846(34.1)$ & 71,834 & 12 & 16.7 & 2 & 2.8 \\
\hline Birth length & $45(0.4)$ & & & & & & & & & & & & \\
\hline$<50 \mathrm{~cm}$ & & $1150(19.1)$ & 41,531 & 24 & 57.8 & 6 & 14.4 & $1691(30.3)$ & 65,635 & 22 & 33.5 & 10 & 15.2 \\
\hline $50-51 \mathrm{~cm}$ & & $2224(36.9)$ & 81,047 & 35 & 43.2 & 15 & 18.5 & 2260 (40.6) & 88,007 & 19 & 21.6 & 12 & 13.6 \\
\hline $52+\mathrm{cm}$ & & $2658(44.1)$ & 94,903 & 45 & 47.4 & 28 & 29.5 & $1622(29.1)$ & 62,246 & 16 & 25.7 & 4 & 6.4 \\
\hline Gestational age (weeks) & $318(2.7)$ & & & & & & & & & & & & \\
\hline$<38$ & & $787(13.3)$ & 28,107 & 11 & 39.1 & 4 & 14.2 & $682(12.6)$ & 26,217 & 6 & 22.9 & 4 & 15.3 \\
\hline $38-41$ & & $4425(75.0)$ & 159,909 & 86 & 53.8 & 43 & 26.9 & $4060(74.7)$ & 157,623 & 41 & 26.0 & 16 & 10.2 \\
\hline $42+$ & & 688 (11.7) & 24,676 & 6 & 24.3 & 1 & 4.1 & $690(12.7)$ & 26,677 & 9 & 33.7 & 5 & 18.7 \\
\hline Social class at birth & $0(0.0)$ & & & & & & & & & & & & \\
\hline Non-manual & & 1487 (24.6) & 53,682 & 26 & 48.4 & 10 & 18.6 & $1371(24.5)$ & 53,157 & 10 & 18.8 & 5 & 9.4 \\
\hline Self-employed or farmer & & 1085 (17.9) & 40,563 & 14 & 34.5 & 10 & 24.7 & 934 (16.7) & 36,668 & 9 & 24.5 & 4 & 10.9 \\
\hline Manual & & 2976 (49.1) & 106,163 & 55 & 51.8 & 25 & 23.5 & 2828 (50.6) & 109,344 & 31 & 28.4 & 14 & 12.8 \\
\hline Other & & $509(8.4)$ & 17,977 & 9 & 50.1 & 4 & 22.3 & $460(8.2)$ & 17,486 & 7 & 40.0 & 3 & 17.2 \\
\hline Mother's marital status & $24(0.2)$ & & & & & & & & & & & & \\
\hline Married & & $4856(80.3)$ & 175,659 & 85 & 48.3 & 41 & 23.3 & $4432(79.4)$ & 172,159 & 43 & 25.0 & 19 & 11.0 \\
\hline Other & & $1190(19.7)$ & 42,300 & 19 & 44.9 & 8 & 18.9 & $1148(20.6)$ & 44,027 & 14 & 31.8 & 7 & 15.9 \\
\hline Adult social class & $155(1.3)$ & & & & & & & & & & & & \\
\hline Non-manual & & $2251(37.7)$ & 82,812 & 35 & 42.2 & 15 & 18.1 & $2940(53.3)$ & 114,493 & 36 & 31.4 & 15 & 13.1 \\
\hline Self-employed or farmer & & 870 (14.6) & 31,768 & 9 & 28.3 & 6 & 18.9 & $761(13.8)$ & 29,861 & 4 & 13.4 & 1 & 3.3 \\
\hline Manual & & 2578 (43.2) & 93,231 & 49 & 53.1 & 23 & 24.9 & $1540(27.9)$ & 59,322 & 12 & 20.2 & 9 & 15.2 \\
\hline Other & & 275 (4.6) & 9,024 & 10 & 110.8 & 5 & 55.4 & $280(5.1)$ & 10,578 & 5 & 47.3 & 1 & 9.5 \\
\hline
\end{tabular}

Adult marital status

$155(1.3)$ 
Table 3: Hazard ratios for completed suicide, overall and via violent methods only, by early life and later life characteristics in Swedes born 1915-1929 and followed from 1960 till $2002(n=11,650)$.

\begin{tabular}{|c|c|c|c|c|c|c|c|c|c|c|c|c|}
\hline \multirow[b]{3}{*}{ Characteristic } & \multicolumn{6}{|c|}{ All suicides } & \multicolumn{6}{|c|}{ Suicides via violent methods } \\
\hline & \multicolumn{3}{|c|}{ Minimally adjusted $^{1}$} & \multicolumn{3}{|c|}{ Fully adjusted $^{2}$} & \multicolumn{3}{|c|}{ Minimally adjusted $^{1}$} & \multicolumn{3}{|c|}{ Fully adjusted $^{2}$} \\
\hline & $\mathrm{HR}(95 \% \mathrm{CI})$ & $\begin{array}{l}\text { Wald } \\
\text { test p- } \\
\text { value }\end{array}$ & $\begin{array}{c}\mathrm{p} \text {-value } \\
\text { for } \\
\text { trend }\end{array}$ & $\mathrm{HR}(95 \% \mathrm{CI})$ & $\begin{array}{l}\text { Wald } \\
\text { test p- } \\
\text { value }\end{array}$ & $\begin{array}{c}\mathrm{p} \text {-value } \\
\text { for } \\
\text { trend }\end{array}$ & $\mathrm{HR}(95 \% \mathrm{CI})$ & $\begin{array}{l}\text { Wald } \\
\text { test p- } \\
\text { value }\end{array}$ & $\begin{array}{c}\mathrm{p} \text {-value } \\
\text { for } \\
\text { trend }\end{array}$ & $\operatorname{HR}(95 \% \mathrm{CI})$ & $\begin{array}{l}\text { Wald } \\
\text { test p- } \\
\text { value }\end{array}$ & $\begin{array}{c}\mathrm{p} \text {-value } \\
\text { for } \\
\text { trend } \\
\end{array}$ \\
\hline \multicolumn{13}{|l|}{ Sex } \\
\hline Male & $1.82(1.32-2.51)$ & $<0.001$ & & $1.79(1.12-2.87)$ & 0.02 & & $1.92(1.20-3.07)$ & 0.007 & & $1.83(1.12-2.99)$ & 0.02 & \\
\hline Female & 1.00 & & & 1.00 & & & 1.00 & & & 1.00 & & \\
\hline \multicolumn{13}{|c|}{ Maternal characteristics } \\
\hline \multicolumn{13}{|c|}{ Maternal age (years) } \\
\hline $15-24$ & 1.00 & & & 1.00 & & & 1.00 & & & 1.00 & & \\
\hline $25-34$ & $1.12(0.79-1.60)$ & 0.53 & 0.50 & $1.33(0.72-2.46)$ & 0.36 & 0.57 & $1.41(0.82-2.41)$ & 0.21 & 0.26 & $1.33(0.72-2.46)$ & 0.36 & 0.57 \\
\hline $35+$ & $1.15(0.74-1.79)$ & 0.54 & & $1.25(0.54-2.90)$ & 0.60 & & $1.40(0.72-2.72)$ & 0.32 & & $1.25(0.54-2.90)$ & 0.60 & \\
\hline \multicolumn{13}{|l|}{ Maternal parity } \\
\hline 1 & 1.00 & & & 1.00 & & & 1.00 & & & 1.00 & & \\
\hline $2-3$ & $1.27(0.89-1.83)$ & 0.19 & 0.06 & $1.36(0.79-2.34)$ & 0.26 & 0.32 & $1.36(0.80-2.30)$ & 0.26 & 0.18 & $1.36(0.79-2.34)$ & 0.26 & 0.32 \\
\hline $4+$ & $1.44(0.97-2.13)$ & 0.07 & & $1.40(0.69-2.83)$ & 0.35 & & $1.46(0.81-2.62)$ & 0.21 & & $1.40(0.69-2.83)$ & 0.35 & \\
\hline \multicolumn{13}{|c|}{ Early life physical characteristics } \\
\hline \multicolumn{13}{|c|}{ Birthweight-for-gestational age } \\
\hline Lowest tertile & 1.00 & & & 1.00 & & & 1.00 & & & 1.00 & & \\
\hline Middle tertile & $0.77(0.53-1.12)$ & 0.17 & 0.20 & $0.95(0.55-1.63)$ & 0.85 & 0.70 & $0.94(0.55-1.62)$ & 0.82 & 0.79 & $0.95(0.55-1.63)$ & 0.85 & 0.70 \\
\hline Highest tertile & $0.78(0.54-1.14)$ & 0.20 & & $0.89(0.51-1.57)$ & 0.70 & & $0.93(0.53-1.62)$ & 0.79 & & $0.89(0.51-1.57)$ & 0.70 & \\
\hline \multicolumn{13}{|c|}{ Gestational age (weeks) } \\
\hline$<38$ & $0.76(0.46-1.27)$ & 0.30 & & $0.76(0.36-1.62)$ & 0.48 & & $0.77(0.37-1.62)$ & 0.50 & & $0.76(0.36-1.62)$ & 0.48 & \\
\hline $38-41$ & 1.00 & & 0.99 & 1.00 & & 0.76 & 1.00 & & 0.83 & 1.00 & & 0.76 \\
\hline $42+$ & $0.75(0.44-1.27)$ & 0.28 & & $0.64(0.28-1.46)$ & 0.29 & & $0.67(0.29-1.53)$ & 0.34 & & $0.64(0.28-1.46)$ & 0.29 & \\
\hline \multicolumn{13}{|c|}{ Early life socioeconomic characteristics } \\
\hline \multicolumn{13}{|c|}{ Social class at birth } \\
\hline Non-manual & 1.00 & & & 1.00 & & & 1.00 & & & 1.00 & & \\
\hline $\begin{array}{l}\text { Self-employed or } \\
\text { farmer }\end{array}$ & $0.87(0.51-1.46)$ & 0.59 & 0.18 & $1.29(0.60-2.77)$ & 0.52 & 0.44 & $1.27(0.61-2.63)$ & 0.52 & 0.37 & $1.29(0.60-2.77)$ & 0.52 & 0.44 \\
\hline Manual & $1.19(0.81-1.75)$ & 0.67 & & $1.26(0.70-2.27)$ & 0.44 & & $1.30(0.72-2.33)$ & 0.38 & & $1.26(0.70-2.27)$ & 0.44 & \\
\hline Other & $1.35(0.75-2.44)$ & 0.32 & & $1.36(0.54-3.44)$ & 0.51 & & $1.39(0.57-3.43)$ & 0.47 & & $1.36(0.54-3.44)$ & 0.51 & \\
\hline \multicolumn{13}{|l|}{ Mother's marital status } \\
\hline Married & 1.00 & & & 1.00 & & & 1.00 & & & 1.00 & & \\
\hline Other & $1.04(0.71-1.53)$ & 0.83 & & $1.32(0.66-2.66)$ & 0.43 & & $1.02(0.58-1.80)$ & 0.95 & & $1.32(0.66-2.66)$ & 0.43 & \\
\hline
\end{tabular}

Later life socioeconomic characteristics

Adult social class 
Non-manual

Self-employed or

farmer

Manual

Other

Adult marital status

Married

Other

1: Adjusted for sex, age and calendar period

2: Additionally adjusted for all other variables in the table.

$0.55(0.31-1.00) \quad 0.05$

$1.00(0.71-1.40) \quad 0.99$

0.23
$0.68(0.30-1.57) \quad 0.37$

$1.18(0.71-1.97) \quad 0.52$

0.34

$0.70(0.31-1.60) \quad 0.40$

$1.26(0.76-2.10) \quad 0.37$

$2.03(0.84-4.87) \quad 0.12$

0.17

$0.68(0.30-1.57)$

0.37

$1.18(0.71-1.97) \quad 0.52$

$1.48(0.61-3.34)$

0.39

1.00

1.00

1.00

$2.38(1.45-3.93)$ 
Table 4: Hazard ratios for completed suicide via violent methods by birthweight-forgestational age in Swedes born 1915-1929 and followed from 1960 till 2002.

\begin{tabular}{|c|c|c|c|c|}
\hline \multirow[b]{2}{*}{ Characteristic } & \multicolumn{2}{|c|}{ Minimally adjusted $^{1}$} & \multicolumn{2}{|c|}{ Fully adjusted $^{2}$} \\
\hline & $\mathrm{HR}(95 \% \mathrm{CI})$ & $\begin{array}{c}\text { Wald } \\
\text { test } p \text {-value }\end{array}$ & $\mathrm{HR}(95 \% \mathrm{CI})$ & $\begin{array}{c}\text { Wald } \\
\text { test } p \text {-value }\end{array}$ \\
\hline \multicolumn{5}{|l|}{ Males $(n=6057)$} \\
\hline Below median & $0.81(0.46-1.42)$ & 0.46 & $0.87(0.49-1.53)$ & 0.52 \\
\hline Above median & 1.00 & & 1.00 & \\
\hline \multicolumn{5}{|c|}{ Females $(\mathrm{n}=5593)$} \\
\hline Below median & $2.02(0.88-4.63)$ & 0.10 & $2.03(0.87-4.71)$ & 0.10 \\
\hline Above median & 1.00 & & 1.00 & \\
\hline
\end{tabular}

1: Adjusted for sex, age and calendar period.

2: Additionally adjusted for all other variables in Table 3. 